\title{
CLINICAL AND ELECTROENCEPHALOGRAPHIC INVESTIGATIONS IN MYOCLONIC CEREBELLAR DYSSYNERGIA
}

\author{
BY
}

\author{
A. KREINDLER, E. CRIGHEL, and I. POILICI
}

From the I. P. Pavlov Neurological Institute of the Rumanian Academy of Sciences, Bucharest

Clinical and anatomical evidence hitherto published on Ramsay Hunt's (1921) myoclonic cerebellar dyssynergia has not succeeded in establishing the nosological place of this clinical entity, which van Bogaert considers to be a cerebellar syndrome with a superimposed myoclonic epilepsy. However, the clinical and electroencephalographic evidence does not permit such a conclusion. The case published by Cristophe and Rémond (1951), followed later by an anatomical study (Christophe and Gruner, 1956), presented cerebellar manifestations associated with typical electroclinical myoclonus, synchronous and symmetrical discharges of spike-and-wave and polyspike-and-wave complexes, and of myoclonus activated by intermittent photic stimulation, whereas the cases reported by Alajouanine, Scherrer, Contamin, Marteau, and Calvet (1955), Daum, Lecasble, and Foncin (1953), and De Risio (1957 had no electroencephalographic accompaniments to the myoclonic discharge. The case reported by Daum and others (1953) did not even display a cerebellar syndrome 17 years after the onset of the disease. The disease sometimes follows a prolonged monosymptomatic course, irrespective of its having begun with cerebellar manifestations or with myoclonus. The E.E.G. and clinical evidence reported in the present paper is a contribution to its pathogenesis and nosological classification.

\section{Case Reports}

We examined clinically and electroencephalographically a girl displaying the typical syndrome, which was also seen in her parents and two brothers, aged 12 and 7 years respectively.

In the case of Elisa P., aged 15 years, no occupation, the disease appeared at the age of 11 , with a nocturnal generalized convulsive seizure. She had similar convulsive seizures during the following nights. Four weeks after the onset of the disease it was noticed that during the day-time the patient displayed sudden jerks, which made her fall. These jerks were followed by a discharge of generalized myoclonus (involving the limbs and face), associated sometimes with, sometimes without, displace- ment of the limb segment. Despite the patient's statement that such seizures during the day were associated with loss of consciousness those who witnessed them stated that the patient spoke in a broken voice and asked not to be assisted as she was able to get up by herself. It may be assumed either that she did not wholly lose consciousness or that its loss was but transitory. These seizures were more frequent in the morning, particularly when the patient got out of bed, and in the evening. They occurred about five or six times every day. At the same time the patient noticed the onset of a tremor and small muscular jerks which interfered with each movement of the hands. She became clumsy and dropped things. Her voice was broken. Jerks were likewise present in the muscles of the face and distal extremity of the limbs, with or without segmental displacement; they were in no way related to falls, but emotional upset and even the smallest voluntary act aggravated them. For the past three years she had had no more generalized seizures? but the myoclonic manifestations had become more intense. It was also noticed that her legs suddenly gave way during walking, thereby making her fall.

On neurological examination, the patient stood upright on a wide base, and she could walk also on a wide base. It was noticed that one of the knees, either the right or the left, suddenly gave way involuntarily from time to time; muscular jerks and oscillations of the trunk were also present. Active movement was possible in all limb segments, but it was interfered with by muscular jerks affecting mainly the distal extremities of the limbs. There was hypotonia in the lower limbs. The ankle jerks were abolished. The plantar cutaneous reflex was normal; the right upper abdominal reflex was the only one left unimpaired but it was rapidly exhausted. There was normal sensibility, both superficial and deep. The patient exhibited the following cerebellar signs: intention tremor in the forefinger-nose test, bilateral adiadokokinesis, with the arms stretched forward there was a rapid tremor of the fingers with a small amplitude, dysmetria and hypermetria were elicited by all the tests, asynergia of the trunk in Babinski's overturning test, bilateral Stewart Holmes reaction. Speech was broken and somewhat explosive. Writing was macrographic, with an irregular, quavering touch, so that some strokes were invisible due to a jerk displacing the whole limb.

When lying the patient displayed no tremor and the muscular jerks were very infrequent. In the upright 
position they affected all the muscle groups, including the face in the form of fasciculations. The myoclonus was irregular, asymmetrical and it was exaggerated by exertion and emotion. Sudden jerks of the muscles of the trunk, making the patient fall, followed by myoclonic discharges lasting three or four minutes, without loss of consciousness, were noticed. There was nystagmus on lateral gaze.

Psychiatric examination disclosed puerilism and slight behaviour disorder.

Laboratory examinations were normal, apart from a mild normochromic anaemia. The cerebrospinal fluid was normal.

Air encephalography revealed slight enlargement of the third ventricle and of the aqueduct of Sylvius. Air was present in the major cistern as well as in the prepeduncular cistern.

Electroencephalographic examination showed a rather polymorphous background tracing (Fig. 1); it consisted of a rapid rhythm of $14 \mathrm{c}$./ $/ \mathrm{sec}$. and of waves in the theta band at the rate of $5 \mathrm{c}$./sec., either isolated or in outbursts, and had the appearance of positive sharp waves with a bilateral temporo-central and temporo-occipital location. They sometimes formed paroxysmal discharges with a low frequency, lasting between four and 10 seconds, without the patient losing consciousness. The generalized paroxysm was characterized by another type of discharge, which was very frequent and brief (one to two sec.) occurring at regular intervals and characterized by generalized outbursts of spike-and-wave, polyspike-andwave, or sinusoidal waves with a frequency of $5 \mathrm{c}$. $/ \mathrm{sec}$. (Fig. 1). These discharges were not activated by the intermittent light stimulation and they did not correspond with the myoclonus. During these discharges she answered correctly a question asked in advance and the answer she gave afterwards to a question asked during the discharge was equally correct. When asked a question, she developed myoclonus in the facial muscles before answering, which caused deterioration in the electroencephalographic tracing. The records displayed a close relationship between the facial myoclonus and the answers, but, on the other hand, there was no visible relationship between the discharges and the myoclonus. Myoclonus and fasciculation occurring in other muscle groups displayed the same characteristics (Fig. 3).

Hyperpnoea brought about a slow dysrhythmia in all leads but chiefly in anterior leads.

Largactil (75 mg. daily) brought about an obvious clinical improvement. The myoclonus and fasciculation became less frequent and troublesome. The background activity was irregular, there was a greater number of waves in the theta band, positive sharp waves both isolated and in outbursts, rapid rhythms of $20 \mathrm{c}$./ $/ \mathrm{sec}$., mainly in anterior leads. Though irregular, the generalized paroxysm of spike-and-waves and polyspike-and-waves had a somewhat higher frequency (6 per sec.) (Fig. 2). An intramuscular injection of $0.25 \mathrm{mg}$. adrenaline, administered under the effect of "largactil", did not in any way change the electroencephalographic pattern. An intramuscular injection of $0.2 \mathrm{~g}$. acetylcholine, given under similar conditions, improved the background activity: the positive sharp waves were less numerous and the outbursts were less prolonged, their amplitude was smaller. The generalized discharges (characterized by hypersynchronous waves) had a frequency of four or five per minute and were shorter.

Six days after "largactil" therapy had been discontinued, the electroencephalographic tracing resumed its initial pattern. The positive sharp waves were in greater numbers and in particular the outbursts were more prolonged, displaying a left centro-occipital predominance.

Adrenaline, $0.5 \mathrm{mg}$., given intramuscularly caused no electrocardiographic or electroencephalographic change. Clinically, the myoclonus became more frequent and more generalized. The electroencephalographic and clinical picture remained unchanged after an injection of neoeserin. An injection of $4 \mathrm{mg}$. strychnine did not modify the pattern of the tracings, but the myoclonus became more ample and frequent, particularly when the patient answered questions (Fig. 3).

Delayed mental development of Emmanuel P., aged 12 years, a brother of Elisa P., had been noticed since early childhood. He did not recognize persons around him until he was 4 years of age. He learned the names of objects at the age of 5 . He could not attend school because he was unable to learn or concentrate or observe school discipline. He could learn no trade, nor could he perform any consequent activity. He displayed seizures of psychomotor agitation which sometimes attained great violence.

There was nothing worth mentioning in the child's past history.

A neurological examination was negative.

Psychiatric examination showed a second degree oligophrenia.

Electroencephalographic examination showed lightreactive background activity displaying waves in the alpha band, at the rate of $10 \mathrm{c}$. $/ \mathrm{sec}$., waves in the theta band at the rate of $4 \mathrm{c}$. $/ \mathrm{sec}$, , particularly in anterior leads. The tracing was rather poorly organized for the child's age. Discharges lasting one or two seconds were noticed to appear against this background, characterized by atypical spike-and-wave complexes at the rate of $4 \mathrm{c}$./sec., slow biphasic spikes or hypersynchronous biphasic waves attaining the greatest amplitude in the left temporo central lead (Fig. 4). The discharges were not accompanied by any myoclonic manifestations. Hyperpnoea exerted no influence.

Thirty minutes after the ingestion of $50 \mathrm{mg}$. "largactil", the child was drowsy. Fifteen minutes later, he became clumsy in the performance of voluntary actions. Each movement was interfered with by myoclonus, similar to that displayed by his sister. The electroencephalographic tracings exhibited marked alterations. Biphasic spikes or even slow isolated spike-and-waves were noticed, chiefly in central leads. Spike-and-wave discharges were more frequent and persistent (Fig. 5). Paroxysmal dysrhythmic periods were noticed in the central region lasting 20 to 27 seconds, characterized by slow waves, positive sharp waves, positive spikes with an inconstant frequency. Phase reversal could be elicited between the central electrodes (Fig. 6).

After a subcutaneous injection of adrenaline $(0.5 \mathrm{mg}$.) 


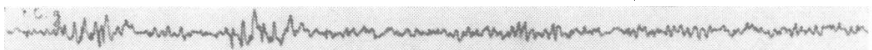

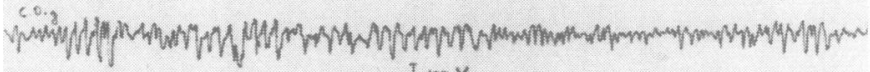
क T., I $100, \mathrm{~s}$.

F".

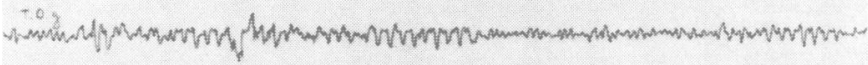
c.c.d

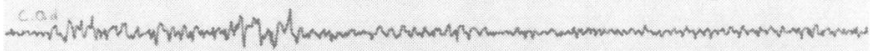

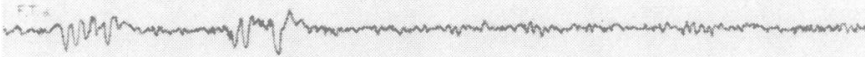

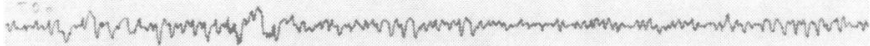
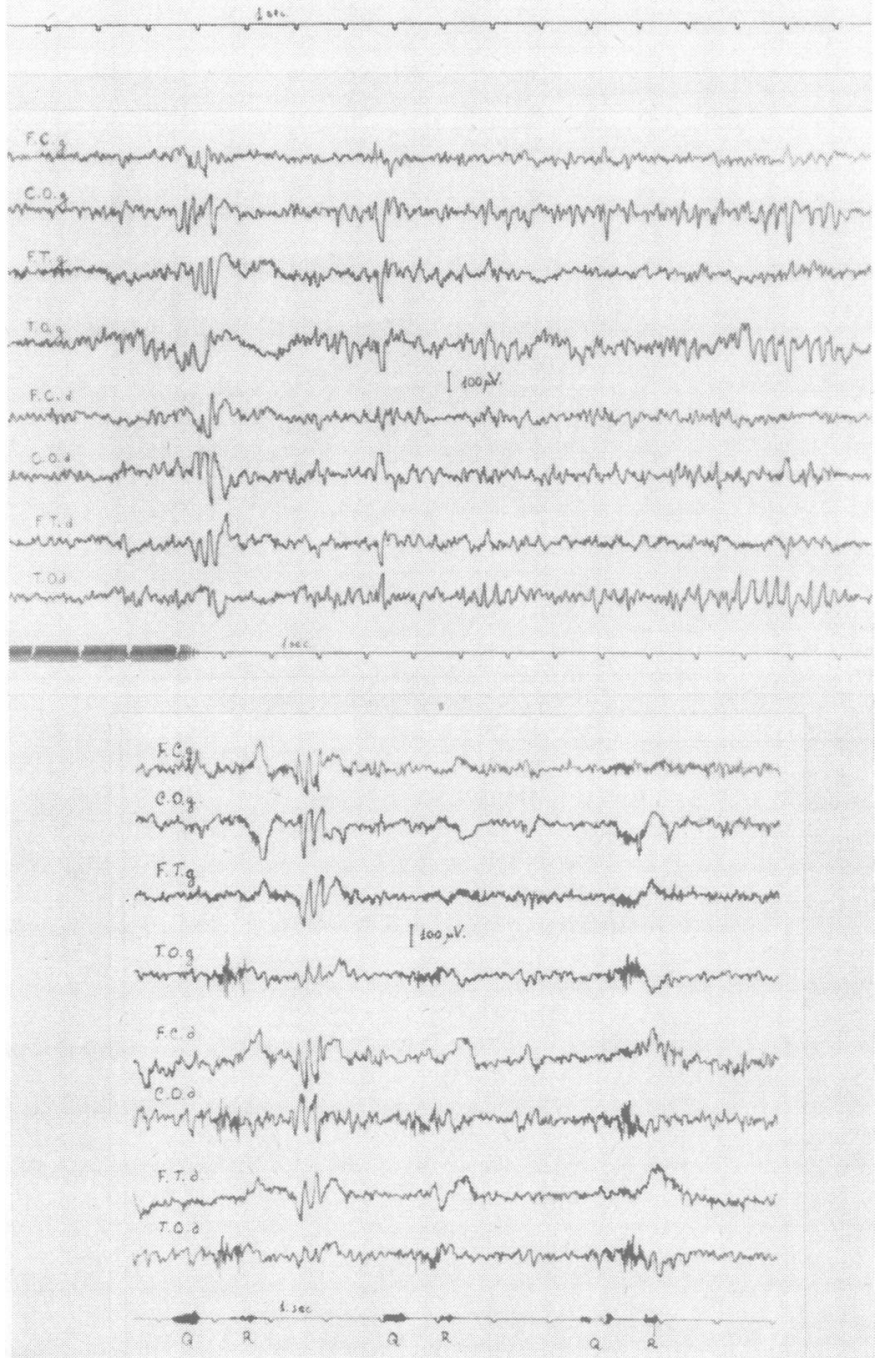

Fig. 1.-Elisa P. Polymorphous background tracings: rapid rhythm at the rate of $14 \mathrm{c}$. $/ \mathrm{sec}$., waves in the band at the rate of $5 \mathrm{c}$. $/ \mathrm{sec}$. either isolated or in outbursts. Paroxysmal outbursts of positive sharp waves with a bilateral temporo-central and temporooccipital location, lasting four to 10 seconds. Brief discharges of generalized outbursts, spike-and-waves, polyspike-and-waves, or sinusoidal waves with a frequency of $5 \mathrm{c}$./sec.

FIG. 2.-Elisa $P$. Largactil (75 mg. daily) causes greater alteration in the tracing: a more irregular background activity, a greater $\square$ number of theta waves, sharp waves, and rapido rhythms of $20 \mathrm{c}$./sec. in anterior leads.

Fig. 3.-An injection of $4 \mathrm{mg}$. strychnine does not alter the appearance of the tracings, but myoclonus is more ample and more frequent chiefly when the patient answers questions. 
Fig. 4.-Emmanuel $P$. A poorly organized electroencephalographic tracing for his age. Discharges lasting one or two seconds of atypical spike-and-waves complexes at the rate of $4 \mathrm{c}$./sec., attaining the greatest amplitude in the left temporo-central derivation.

Fig. 5.-Emmanuel $P$. Thirty minutes after the ingestion of $50 \mathrm{mg}$. "largactıl" the tracings exhibit marked alterations. Biphasic spikes, or even slow isolated spike-and-waves are seen. Spike-and-wave discharges are more frequent and persistent.
Fig. 6.-Emmanuel $P$. Same situation as in the former figure. Paroxysmal dysrhythmia appears in the central region, lasting 20 to 22 seconds, characterized by slow, positive, sharp waves and positive spikes. Phase reversal can be noticed between the central electrodes.
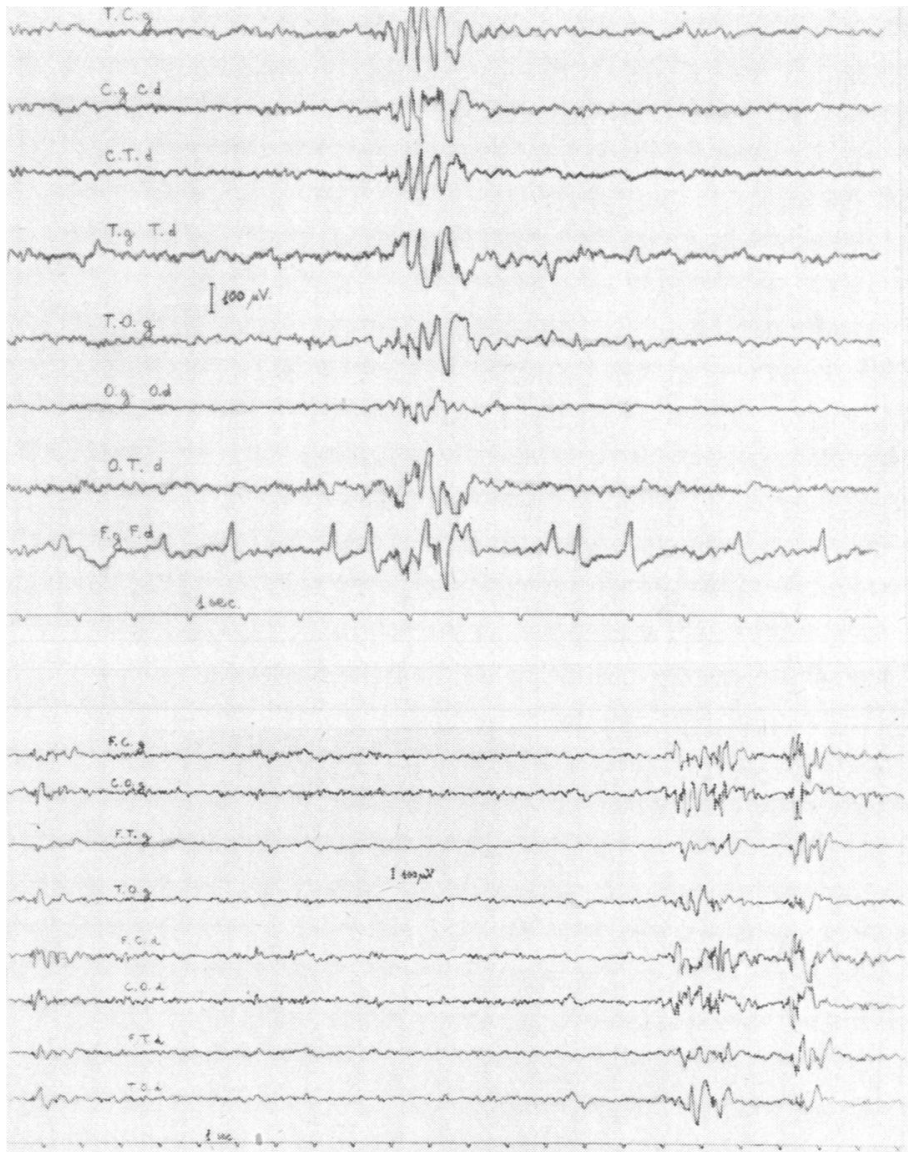

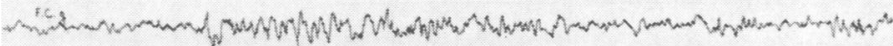

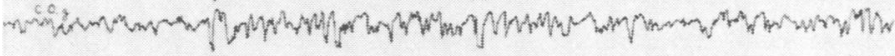

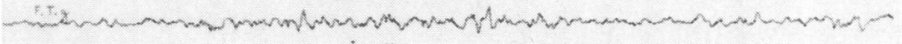
- $x-1$

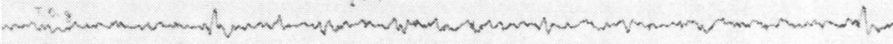

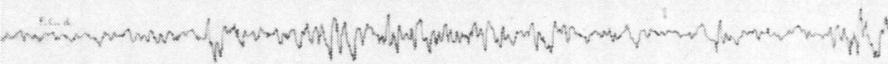

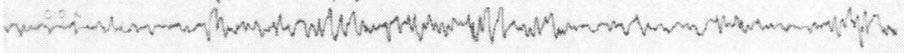

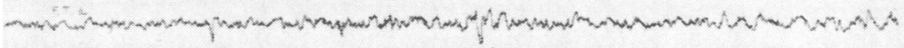
Moth

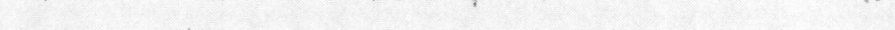


the tracings displayed a score of sharp waves, isolated and grouped, slow biphasic spikes, waves in the theta band at the rate of $4 \mathrm{c}$. $/ \mathrm{sec}$. No generalized discharge of spike-and-waves was visible any more.

Florian P., aged 7 years, was the third child. He displayed somewhat marked mental retardation.

Neurological examination elicited an oscillating gait and dysmetria and intention tremor, chiefly in the limbs on the right side.

Air encephalography showed a slight degree of internal hydrocephalus and a considerable amount of air in the prepeduncular cistern.

The electroencephalogram revealed normal tracings with sparse bi- and triphasic spikes in the central regions. The background activity in posterior leads was somewhat slow (8 c./sec.). Hyperpnoea gave rise to ample, sinusoidal, symmetrical, generalized waves, within normal limits for the patient's age. Intermittent light stimulation did not alter the tracing.

A dose of $50 \mathrm{mg}$. "largactil" did not modify the tracings but a discharge resembling the ones elicited in his sister was noticed.

Marin P., the children's father, aged 47 years, a laboratory assistant, exhibited no subjective disorder. His father (the children's grandfather), who died with psychiatric disorders when aged 75 years, had had syphilis. No case of epilepsy or other neurological diseases was noted in the father's family.

Neurological examination showed loss of the tendon reflexes in the lower limbs and diminution of the tendon reflexes in the upper limbs. Gyratory nystagmus was present on right lateral gaze.

The electroencephalographic tracings were normal.

Zinca P., the children's mother, aged 45 years, no occupation, was mentally deficient. There were no neurological factors worth mentioning in her family. The electroencephalographic tracings were within normal limits.

\section{Discussion}

The clinical picture, the course of the disease, and the alterations in electroencephalographic tracings exhibited by the first patient suggest myoclonic cerebellar dyssynergia. The onset is somewhat unusual as the first manifestations consisted of nocturnal generalized convulsive seizures. In her two brothers the diagnosis is more difficult. In the case of Emmanuel P., the alterations in electroencephalographic tracings are very much like those found in his sister. The untoward effect of "largactil", which, in the case of Emmanuel caused cerebellar disorders and myoclonia, is in contrast to the beneficial effect upon the clinical symptoms elicited in Elisa, though both children displayed the same electroencephalographic alterations, chiefly an aggravation of centralencephalic discharges with a temporal projection, which sometimes have the actual appearance of seizures of temporal epilepsy lacking any clinical manifestation. We believe that Emmanuel is likewise a case of
Ramsay Hunt's disease, though at an earlier stage, before the onset of clinical cerebellar or myoclonic manifestations. The mild cerebellar disorders displayed by the youngest child, Florian, and by their father are more difficult to interpret. The very slight electroencephalographic disorders elicited in the case of Florian and the absence of any alteration in the father in no way rule out the diagnosis of dyssynergia cerebellaris myoclonica.

In the case published by Daum and others (1953) there was only a generalized dysrhythmia without any of the characteristic manifestations of myoclonic epilepsy even after intermittent light stimulation. The patient of Alajouanine and others (1955) displayed only posterior theta waves at the rate of 6 c./sec., while De Risio's patient (1957) exhibited theta waves of low amplitude in bilateral temporal leads. In the latter patient, intermittent light stimulation as well as photo-cardiazol activation did not give rise to manifestations of myoclonic epilepsy. The youngest child of the $P$. family may be considered as having the disease in its initial stage (cerebellar disorders, generalized discharge determined by "largactil", bi- and triphasic spikes in the central region). The father may be affected with another syndrome of the group of cerebellospinal degenerations, but this is difficult to ascertain in the absence of anatomical data.

The delayed mental development in the children must be specially mentioned, particularly in the two brothers and in the mother.

In the case of Elisa, the myoclonus had no electro encephalographic accompaniments; nor were the generalized and synchronous spike-and-wave or polyspike-and-wave discharges accompanied by myoclonus in the sister and in the elder brother. Intermittent light stimulation did not cause either electroencephalographic discharges or clinical myoclonus. Such characteristics compel us to admit that there is a physiopathological difference between myoclonus in Hunt's disease and in myoclonic epilepsy. According to Greenfield (1954), there may be different types of myoclonia, but insufficiently studied. Discrepancies might be explained by different modalities of discharges from the focus. In our patient we have pointed out the antagonism existing between the action of "largactil" and that of adrenaline. In the case of Elisa, "largactil" almost completely abolished the myoclonus, but it exerted an untoward influence upon the electroencephalographic tracings, whereas adrenaline obviously aggravated myoclonus. In the case of Emmanuel, "largactil" determined the onset of clinical myclonus which was not present before. It might be inferred that myoclonus is determined by a hyperexcitable focus at the level of the mesodiencephalic reticular 
formation. Discharges towards the brain cortex induce the typical spike-and-wave or polyspike-andwave alteration. Discharges towards the motor neurone in the anterior horn of the spinal cord produce clinical myoclonus. Each discharge from the focus is therefore directed towards the cortex and towards the spinal cord. We have pointed out before (Kreindler, Broşteanu, and Poilici, 1957) that in petit mal there is an analogous mechanism. In myoclonic epilepsy due either to a great reticular excitability or to the fact that the cortex and the peripheral motoneurone have the same degree of hyperexcitability, each discharge from the focus has cortical and peripheral accompaniments. The same phenomenon is sometimes liable to occur in myoclonic cerebellar dyssynergism (Cristophe and Rémond, 1951). Reticular dysfunction or different degrees of cortical and spinal excitability cause the discharge from the focus to have but a single accompaniment, i.e., either cortical or peripheral. We are inclined to think that the cause is rather related to reticular dysfunction. Both "largactil" and adrenaline have a considerable reticular action, and in the two children they influenced the myoclonic discharges. In the case of Elisa, who displayed myoclonus, "largactil" exerted a beneficial influence upon the peripheral discharge whereas adrenaline aggravated it. In the case of Emmanuel, who had no peripheral discharges, "largactil" induced such discharges. In both of them "largactil" brought about an aggravation of electroencephalographic alterations and particularly of generalized spike-and-wave discharges. The interparoxysmal alterations in electrogenesis are due to lesions of the reticular substance while differences in tracings are related to different morphological and functional alterations of the reticular substance.

The importance of the excitability of the motoneurone in the clinical efficiency of discharges from the focus is evident from the fact that strychnine, a substance exerting a prevailingly spinal action, causes an aggravation of myoclonus.

It might therefore be inferred that the different clinical and electroencephalographical aspects of dyssynergia cerebellaris myoclonica are determined by the diversity of morphological and functional alterations in the reticular substance and cerebellum. Transition forms are found between cases with but one symptom and those displaying the full picture of the disease.

\section{REFERENCES}

Alajouanine, T., Scherrer, J., Contamin, F., Marteau, R., and Calvet, J.' (1955). Rev. neurol., 93, 577.

Cristophe, J., and Gruner, J. (1956). Ibid., 95, 297.

C., and Rémond, A. (1951). Ibid., 84, 256 .

Daum, S., Lecasble, R., and Foncin, J. F. (1953). Ibid., 89, 287.

Daum, S., Lecasbe, R. Riv. sper. Freniat.. 81, 941 .

Greenfield, J. G. (1954). The Spino-Cerebellar Degenerations, p. 79. Blackwell Scientific Publications, Oxford.

Hunt, J. R. (1921). Brain, 44, 490.

Kreindler, A., Broșteanu, R., and Poilici, I. (1957). Stud. Cercet. Neurol., 2, 461. 